\title{
SOCIAL NETWORK ANALYSIS AND DYADIC IDENTIFICATION IN THE CLASSROOM
}

\author{
CRISTIANO DE OLIVEIRA MACIEL \\ Pontifícia Universidade Católica do Paraná, Curitiba, Paraná, Brazil.
}

To cite this paper: Maciel, C. O. (2018). Social network analysis and dyadic identification in the classroom. Revista de Administração Mackenzie, 19(1). doi 10.1590/1678-6971/eRAMG180051

Submission: Apr. 18, 2017. Acceptance: Sep. 14, 2017.

\section{(cc) BY} This is an open-access article distributed under the terms of the Creative Commons Attribution License.

\footnotetext{
This paper may be copied, distributed, displayed, transmitted or adapted if provided, in a clear and explicit way, the name of the journal, the edition, the year and the pages on which the paper was originally published, but not suggesting that RAM endorses paper reuse. This licensing term should be made explicit in cases of reuse or distribution to third parties. It is not allowed the use for commercial purposes.

Este artigo pode ser copiado, distribuído, exibido, transmitido ou adaptado desde que citados, de forma clara e explícita, o nome da revista, a edição, o ano e as páginas nas quais o artigo foi publicado originalmente, mas sem sugerir que a RAM endosse a reutilização do artigo. Esse termo de licenciamento deve ser explicitado para os casos de reutilização ou distribuição para terceiros. Não é permitido o uso para fins comerciais.
} 


\section{ABSTRACT}

Purpose: For this work I established as research objective the examination of antecedents (i.e., similarity of structural position, competence and sociability) and the consequences (i.e., formation of work group) of dyadic identification among students on a Business Administration course at a private University.

Originality/Value: Identification has been examined anthropomorphically in the relationship between employee and organization or between employee and work team. However, organizations and teams are not human beings. I propose to investigate identification at the dyadic level, indeed among people, to transcend that barrier.

Design/methodology/approach: I employed the sociometric survey as a method. Data were collected in two phases, with an interval of 12 months $\left(t_{0}\right.$ and $\left.t_{1}\right)$. I tested the hypotheses by means of the LR-QAP non-parametric technique.

Findings: The results allowed me to point out that structural equivalence and similarity of deferences for competence and for sociability, influence dyadic identification. In examining the work groups' training on completion of the course, I confirmed the hypothesis on the influence of dyadic identification, but also found that such groups are mainly formed by students who share the same contacts and are very similar in sociability (fun) and slightly similar in terms of competence deferences. Structural equivalence, deferences of competence, and deference to sociability constitute a structural-deferential basis for social judgment and construction of social profiles and categories that enable comparison between peers and subsequent identification in a non-anthropomorphic way.

\section{KEYWORDS}

Social network analysis. Dyadic identification. Sociometric survey. Students. LR-QAP. 


\section{INTRODUCTION}

The concept of identification has gained greater importance since Social Identity Theory (Tajfel, 1978; Tajfel \& Turner, 1979) and Self-Categorization Theory (Turner, Hogg, Oakes, Reicher, \& Wetherell, 1987) were launched. While social identity is atomized as a reflection of how one sees oneself, social identification is constituted in its cognitive dimension by the intensity with which someone defines themselves as being part of a particular social referent (Tajfel, 1978; Turner et al., 1987). Although it is recognized that identity always has a social referent as its basis, it is the concept of identification that explains how someone is depersonalized in some measure by categorizing themselves as a member of a particular group with which he or she perceives a greater similarity between themselves and those belonging to this group (Hornsey, 2008).

The importance of the study of identification is centered on the effect it has on how people behave at work in different contexts (Sluss \& Ashforth, 2008). Several studies show the impact of identification on work performance, well-being, and learning (e.g., Millward \& Postmes, 2010; Mishra \& Bhatnagar, 2010; Fombelle, Jarvis, Ward, \& Ostrom, 2012). More recently, the interest of several researchers has caused scholars to no longer look only at the organization, but at many other foci of identification (Knippenberg \& Schie, 2000; Jones \& Volpe, 2011; Wieseke, Kraus, Ahearne, \& Mikolon, 2012). For instance, Lee, Farh, and Chen (2011) investigated identification with working groups, and Johnson and Ashforth (2008) investigated the workers' identification with their clients.

It is worth noting that, with the exception of a few studies, such as those of Johnson and Ashforth (2008), the most severe limitation in this research area is the restriction to anthropomorphized referents. On the one hand, organizations, working groups, and even artifacts are treated as if they were humans (i.e., anthropomorphized) (e.g., Marra, Fonseca, \& Marques, 2014; Maciel \& Camargo, 2015). On the other hand, identification with other people has been overlooked, disregarding that such a phenomenon is the product of the relationships between human social actors (Obst, White, Mavor, \& Baker, 2011; Schmid \& Muldoon, 2015; Sluss \& Ashforth, 2007, 2008). Therefore, I propose that research on this type of social connection be moved from the collective level (i.e., organizations and groups), typical of Social Identity Theory, to the dyadic level (i.e., between people), the level of interactions between peers of social actors. 
In keeping with the previous argument that points out a gap in this field of research, my intention is to contribute to approach identification as a dyadic relational phenomenon (Rink \& Ellemers, 2007, 2008; Burgoon, Le Poire, \& Rosenthal, 1995) and to investigate its sources and consequences. According to the need for a de facto relational approach, I chose the Social Network Analysis Perspective (Kilduff, Tsai, \& Hanke, 2006) to investigate dyadic identification in a Business Administration course classroom. The social relationships established inside an educational space such as a classroom have profound implications on the subjectivity and behavior of students (Dawson, 2008; Conti \& Doreian, 2010; Neal, Neal, \& Cappella, 2016). These implications have already been proven in divergent academic performances (Ortiz, Hoyos, \& López, 2004), cigarette smoking (Steglich, Sinclair, Holliday, \& Moore, 2012), ethnic segregation (Leszczensky \& Pink, 2015), and in how the actor sees himself and others (Huitsing, Veenstra, Sainio, \& Salmivalli, 2012). Thus, this context adequately serves the purposes of my intended theoretical contribution. The classroom is an organized space, but without bureaucratically imposed divisions (Boocock, 1978), which facilitates the choice of contacts and types of social relationships that are to be cultivated (Marsden, 2011; Borgatti, Everett, \& Johnson, 2013).

More specifically, I established the following research objective: to examine antecedents (i.e., the similarity of structural positions - extracted from interaction networks - and of sociability and competence - extracted from deference networks) and one of the consequences of dyadic identification (i.e., the formation of final course assignment groups) among students of a Business Administration class at a private university. The choice of interaction and deference networks as antecedents relied on the fact that identification essentially results from social comparison (Hornsey, 2008). These comparisons occur in direct material interactions and through symbolic interactions. The comparison at tie level requires that we map deferences (symbolic appreciations that do not depend on material interactions). The comparison, in turn, which occurs at the structural level between positions extracted from interaction networks (essentially material), requires mapping of the ties pattern (Torló \& Lomi, 2017).

The networks of interaction, sociability, competence, and identification were mapped in the first phase $\left(t_{0}\right)$, and the formations of the final course assignment groups were mapped 12 months later in $\left(t_{1}\right)$. I examined the network of interaction patterns to extract structural measures of prominence, cohesion, intermediation, and position (Nooy, Mrvar, \& Batagelj, 2005) and the deference networks (Lomi \& Torló, 2014) of competence and sociability 
of all classmates in order to extract relational measures at tie levels. Competence and sociability are considered to be the two main dimensions of social judgment in interpersonal relationships (Kervyn, Yzerbyt, \& Judd, 2010; Fiske, Cuddy, \& Glick, 2012).

\section{SOCIAL NETWORK ANALYSIS AND POSSIBILITIES TO INVESTIGATE DYADIC IDENTIFICATION}

SNA (Social Network Analysis) is an unfortunate and controversial acronym for the breadth of knowledge that has been aggregated by researchers who adopt a non-atomized perspective in the investigation of ties and ties patterns between intra and interorganizational network agents (Borgatti, Brass, \& Halgin, 2014; Borgatti \& Halgin, 2011). Granovetter (1990) highlights the myth that Social Network Analysis is just an analysis of relational data.

Currently, Social Network Analysis is still seen as a set of techniques for networks' data processing, but is not exclusively restricted to it, as the SNA also encompasses the processing of composition data (attributes of the network's agents) and is constituted by several theories, and even a particular ontology, which gives it the status of a Theory/Methods Package (Emirbayer \& Goodwin, 1994; Borgatti \& Halgin, 2011; Kilduff et al., 2006). Emirbayer (1997) points out that, when following a relational ontology, the researcher adopts a perspective that assumes a world constituted primarily of relations, although without disregarding the attributes of the agents relating to each other (i.e., characteristics of the networks' agents). In agreement, Kilduff et al. (2006) characterize Social Network Analysis as a research program, in the same sense as that argued by Imre Lakatos. This research program has ties and relational structures at its core. Borgatti and Halgin (2011, p. 1169) state that

A network consists of a set of actors or nodes along with a set of ties of a specified type (such as friendship) that link them. The ties interconnect through shared end points to form paths that indirectly link nodes that are not directly tied. The pattern of ties in a network yields a particular structure, and nodes occupy positions within this structure.

The analytical division between relational ties and relational structures expresses a separation of levels, with distinct operationalization concepts 
and possibilities (Kilduff \& Tsai, 2012). Interpersonal ties can be conceptualized and measured directly from the cognition of the network's agents, assessing, for example, the connection strength (Granovetter, 1973), type of information, type of affection, or the creation of social judgments. The pattern of ties or networks, in turn, composes a structure that is not formed primarily at the cognitive level, since the relational structure operates at a level above the tie that is recognized and characterized by the agent. Hence, there is a frequent separation between ties structure and content. This is because the pattern of ties is at the same time the mean and product of the sum of the agents' structural positions. The complexity of the relational structure, especially in large networks, tends to be reduced only through the extraction of sociometric measures. Sociometry deals with metrics produced from social relationships. Nooy et al. (2005) classify different sociometric measures into four groups: prominence, cohesion, brokerage, and structural position.

The consideration of the tie content at the first level and of sociometric measures at the level of relationship structures allows us to evaluate the impact of both the cognitively embodied relations, through the evaluation of agents and of the architecture of social relationships on a more abstract and collective level, in different attitudinal and behavioral variables.

\subsection{Antecedents of Dyadic Identification in the Classroom}

Social identification in social psychology is defined as an individual's belief that they are part of a particular group constituted by elements that operate as a referent for his self-concept (Schmid \& Muldoon, 2015; Tajfel, 1978; Tajfel \& Turner, 1979). Thus, identification is a type of connection of a social actor in relation to a referent, which is expressed by a feeling of similarity, uniqueness, and harmony. What happens with the latter is therefore perceived as a consequence of the actions of the former (Mael \& Ashforth, 1992; Dutton, Dukerich, \& Harquail, 1994). These characteristics are central to the identification scales, which are constituted by two different indicators: i) a similarity relationship that is perceived between the one that feels identified and the foci of his identification; and ii) a synergistic relationship between the two parties, which is also treated as a harmonious coordination or interaction.

The similarity relationship can be both behavioral and attitudinal, and can be manifested in ways of thinking and acting, as well as social and demographic factors (e.g., age, sex, status, academic education) (Dutton et al., 1994; Wieseke et al., 2012; Sluss \& Ashforth, 2008). The synergistic relationship 
highlights that the positive quality of the interactions between who is identified and his foci is also an essential characteristic of identification. Studies on the social identification of workers with their groups or working groups defend that mutual respect, out-of-work relationships, coordination, and integration are also indicators that are required for identification (Dutton et al., 1994). These two characteristics (i.e., similarity and synergy) further distinguish identification as a product of relationships between social actors (Obst et al., 2011).

In the Social Networks Perspective Analysis, it is necessary to consider as identification antecedents both the possibilities of similarities of structural positions at the most abstract level, which are extracted from ties pattern, and the possibilities of similarity deference, which are extracted at the ties level (Lomi \& Torló, 2014). Networks of interaction patterns are constituted by concrete relationships, which necessarily presuppose a direct and material interaction between actors, such as conversations, requests for advice, and meetings between friends. The networks of deference, in turn, are symbolic appreciations, starting from an emitter to a certain receiver, and take into account the attributes of the receiver. Deference can be formed from knowledge, position, skills, physical characteristics, or possessions of the one who is socially evaluated or judged by his/her peers. In sociometric terms, deferences reveal the social judgments of the actor $i$ (sociometric notation for the focal actor or network ego), in relation to its referent $j$ (sociometric notation for the alter ego), and whether the referent $j$ already knows the focal actor $i$. Sociometry deals with metrics produced from social relationships. Nooy et al. (2005) classify the various sociometric measures into four groups: prominence, cohesion, intermediation, and structural position.

In this sense, my central argument is that structural similarity (i.e., our sociometric indicators of prominence, cohesion, intermediation, and structural position) (Nooy et al., 2005), and the similarity of deferences at the tie level (Lomi \& Torló, 2014), increases the likelihood of the actor $i$ identifying himself with the actor $j$ in a given network. This is because these similarity variables produce structural and symbolic appreciation profiles that are common among some and different in relation to others. Consequently, these profiles conform to social categories or groups with certain structural (positional) and relational (e.g., deferential at tie level) characteristics, which show greater or less structural freedom, autonomy, agency capacity, and status. Thus, such categories operate cognitively as a basis for identification and also emotionally, when establishing targets for affection and solidarity toward social actors who are judged as equal by the focal actor (Sluss \& Ashforth, 2008; Hornsey, 2008). 
The first group of sociometric measures to be considered as a structural antecedent of dyadic identification is structural prominence (Nooy et al., 2005). These measures highlight the actors that stand out more than others, regarding the number of contacts (Wasserman \& Faust, 2009). Among the main parameters to evaluate prominence are centrality measures. The degree of centrality, for example, reveals the actors that have the largest number of ties (without discriminating ties sent from ties received). If a focal actor $i$ cites 3 alters $(j, k, l)$, but is also cited by other alters $(m, n, o)$, the degree centrality of $i$ will be 6 . As structural prominence is correlated to perceived social status (Nooy et al., 2005), I infer that if social actors are aware, not of the total network structure, but of their position in a given hierarchy of centrality, they will identify themselves with other actors exhibiting a similar degree of prominence. Thus, similarity of prominence operates as a parameter of self-categorization (Hornsey, 2008; Turner et al., 1987) and a sense of belonging to the group of either more or fewer central actors, thus configuring the first structural basis of dyadic identification in the classroom.

Hypothesis 1: The similarity of degree centrality between two students increases the probability of dyadic identification among them.

The measures of structural cohesion of the focal actor generally refer to the proportion of effective ties when compared to possible ties (Borgatti et al., 2013). If all the alters of actor $i$ are connected between themselves, the local density of such actor will be equal to 1, which represents a $100 \%$ connection between the alters of $i$. More specifically, I argue that when two actors have similar local densities, this structural feature will be a significant basis of self-categorization (Hornsey, 2008; Turner et al., 1987) and dyadic identification. If an actor $i$ realizes that he is immersed in a high or low local density network and there is another actor $k$ presenting the same structural profile, $i$ will be identified with $k$, as well as $k$ with $i$, depending on the similarity of their structural cohesion.

Hypothesis 2: The similarity of local density between two students increases the probability of dyadic identification between them.

Brokerage measures are used to assess to what extent a social actor $i$ operates as a bridge between two contacts $(j, k)$ that have no ties between them. This is an evaluation of the degree of structural freedom of the network agent (Stovel \& Shaw, 2012). The lack of connection between two contacts $(j, k)$, who are connected to a third focal actor $i$, provides abundant opportunities to the latter, mainly due to the fact that obtaining non-redundant information 
is less costly (Granovetter, 1973; Burt, 1992). Non-redundant information consists of inputs of creativity and achievements of objectives that require political articulation (Kadushin, 2012). The most widely used measure in brokerage measurement is called structural holes (Burt, 1992). This measure assigns a coefficient to the proportion of absent ties between the alters of each ego. Similar proportions of structural holes reveal similar profiles of structural freedom and agency capacity in networks. These profiles operate as a social category (Hornsey, 2008) of the well or poorly related, which serve as referents in the evaluation of the similarity of brokerage and subsequent identification with peers.

Hypothesis 3: Similarity of structural holes between two students increases the probability of dyadic identification between them.

The measures of structural positions emphasize the similarities in the patterns of an actor's ties with the patterns of at least one other actor (Wasserman \& Faust, 2009). If a focal actor $i$ has three alters $(j, k, l)$ and another agent $m$ has the same three contacts $(j, k, l)$, it is said that $i$ and $m$, regardless of any contact between them, are perfectly equivalent in terms of social position. The main measure used in assessing the similarity of social positions in networks is structural equivalence (Nooy et al., 2005). This measure reveals the degree of correlation between the patterns of an actor's ties with each other actor in the network. The similarity of positions can also be used in Blockmodeling techniques to create mutually exclusive groups in terms of ties pattern with third parties (Wasserman \& Faust, 2009). Such an assertion suggests that the similarity of structural equivalence conforms to social categories of relationships that serve as the basis for dyadic identification. Mizruchi (1993) reinforces this argument by showing that structural equivalence homogenizes the actors' way of thinking and acting in the network because the expectations of the alters of two particular actors are the same. Therefore, structural equivalence will be a significant predictor of dyadic identification in the classroom.

Hypothesis 4: Similarity of structural equivalence between two students increases the probability of dyadic identification between them.

As mentioned above, it is not only social interactions networks, through structural measures, that act as a basis for constructing referents for selfcategorization and subsequent identification. Deference networks (Lomi \& Torló, 2014) are also important in explaining identification, as they are symbolic appreciations or social judgments that one actor makes about the 
other before being able to compare characteristic similarities. In this way, it is important to recognize the advances of Social Psychology in this field. Discussions in this area orbit around two central elements in judging one social actor over another: competence and sociability (Kervyn et al., 2010; Fiske et al., 2012). In these terms, someone with the best social judgment would be the one who is considered more competent and more sociable (e.g., cool, fun). Thus, as in several other contexts, these two dimensions of interpersonal judgment seem equally important in the classroom when considered as a basis for identification. The argument is that when two students are referents for one another $(/ i \rightarrow j / j \rightarrow i /)$, and if they judge similarly in terms of competence and sociability (Kervyn et al., 2010), there is a greater likelihood of identification. Therefore, both similarities of competence deference and sociability act as a basis for self-categorization and identification.

Hypothesis 5: Similarity in the network of competence deference between two students increases the probability of dyadic identification between them.

Hypothesis 6: Similarity in the network of sociability deference between two students increases the probability of dyadic identification between them.

\subsection{Working Groups as a Result of Dyadic Identification in the Classroom}

Considering the context of the classroom of the Business Administration course, this study also aimed at verifying if the mutual identification between students could explain the presence of both in the same final course assignment group. The literature reiterates the influence of relational factors in the performance of working groups (Leung \& Wang, 2015; Hu \& Liden, 2015; Crawford \& Lepine, 2013). However, it is incipient regarding the elements that interfere in the formation of the groups, especially in the absence of rules imposed by bureaucratic organizations (Lee \& Chang, 2013). The few efforts aimed at investigating the antecedents of formation or maintenance of working groups are focused on examining the influence of trust (e.g., Lee \& Chang, 2013). Due to these limitations, I argue that dyadic identification, when mutual, will be a significant predictor of the formation of working groups in the classroom. When the identification is mutual in a given dyad of students, the chances that the two are present in the same group are greater, due to the double stimuli of uniqueness (Mael \& Ashforth, 1992). The Homophily Theory (Leszczensky \& Pink, 2015) also 
favors the idea that mutual identification acts as an imperative for the formation of social ties in educational spaces. More precisely, the force of reciprocity between students in establishing and maintaining some and not other social relationships is what explains the effect of mutual identification on the highest probability that students of the dyad will be present in the same working group (Dahlander \& McFarland, 2013).

Hypothesis 7: Mutual identification between two students increases the probability that they are in the same final course assignment group.

\section{METHODOLOGICAL PROCEDURES}

I collected the data in a classroom of 47 students from the Business Administration course of a private university in Curitiba on two occasions (September 2014 and September 2015) with the same participants $\left(t_{0}\right.$ and $\mathrm{t}_{1}$ ). The research began with three classes, but some students dropped out of two of the classes, and thus only one remained unchanged and allowed for the analysis of the same students on the two occasions. In $t_{0}$, as the professor of the students, I invited everyone to participate in the study by completing a survey with network variables (relationships) and composition variables (attributes) (Wasserman \& Faust, 2009). After 12 months, in $t_{1}$, the students answered questions asking for the names of the final course assignment group members and some other indicators that were not used in this article's data analysis. This time interval was necessary because, in 2014 , the students were in the $5^{\text {th }}$ period, and only in the $7^{\text {th }}$ period would they have to compose the final course assignment groups. The course did not impose or suggest any kind of rule for group formation, and so all students were free to negotiate their participation in one or another group directly with their classmates.

Network data were collected through a survey presenting a list of names of all the students in the class. Therefore, it is worth noting that a network with 47 students, a sufficient and common number in the analysis of networks at dyadic level, facilitated the analysis. The interviewee came across a list with all the names and evaluated each name according to several criteria; therefore, it was imperative that this list of participants not be very extensive. I used four questions to generate four relational matrices: (i) interaction pattern; (ii) dyadic identification; (iii) competence deference; and (iv) sociability deference. In the question about interaction patterns, the respondent would indicate on the list the contacts he was closest to 
(Marsden, 2011), which consisted of up to five classmates to whom he talked every day. The relational matrix formed by this question served to generate four sociometric measures extracted in the analysis with the support of UCINET (c) 6.485 software: degree centrality (prominence), local density (cohesion), structural holes (brokerage), and structural equivalence (position) (Nooy et al., 2005). Relational matrices were constructed as indicated by Borgatti et al. (2013) and have already been used by Maciel, Taffarel, and Camargo (2014).

In the identification question, the student answered the following for each of their 46 classmates: "Check from 1 (Little) to 5 (Very) to what extent you think you resemble this person in thinking and acting, and if you participated in some activity together, you could form a harmonious pair" (Rink \& Ellemers, 2007, 2008; Burgoon et al., 1995). The matrix of these data was recorded in 0 and 1 to classify, for example, identification relationships of focal actor $i$ in relation to $j$. Answers 4 and 5 were recoded as number 1 , and answers 1,2 , and 3 as number 0 . In order to evaluate the competence deference for each of the 46 students, the following statement was used: "Check from 1 (Little) to 5 (Very) to indicate how much this person is efficient in course assignments" (Kervyn et al., 2010). To assess the sociability deference for each of the 46 classmates, the statement was as follows: "Check from 1 (Little) to 5 (Very) how fun you think this person is" (Kervyn et al., 2010). The four networks generated by these data are shown graphically in Figure 1. In each network, the proximities between network agents represent the degree of similarity between them.

The composite data - which I used in the hypotheses test as control variables for other sources of identification, and that appeared in the first survey - were generated from the following questions with their respective alternatives: Age (open question); Academic performance compared to classmates (1, if well below the average, to 5 , if well above the average); School attended before college ( 1 if only public school, 2 if only private school, 3 if mostly public school, 4 if mostly private school); Civil Status (0 if single, 1 if married); English ( 1 if basic, 2 if intermediate, 3 if fluent); Father's education ( 0 if primary or secondary education and 1 if higher education); Father's occupation (1 if public employee, 2 if private company employee, 3 if entrepreneur); Institutional Ties (1 if participating regularly in any church, theater, scout, choir, volunteer work, or similar group and 0 if not); Sex (0 if male and 1 if female); and Work ( 0 if not currently working and 1 if currently working). For the test of hypothesis 7 , I constructed a matrix in which each dyad received as code the number 1 , if the two students 
were in the same assignment group formed in 2015, and 0 if not. As the test of hypothesis 7 was based on symmetric or mutual identification, I created a new identification matrix in which, if two students identified each other, the dyad received a score of 1 , and if not, or if only one part identified with the other, the dyad received a score of 0 . Subsequently, I generated a similarity matrix for the age variable by calculating the dyadic distances and subtracting the resulting value from 1 . For the other nominal variables, I also generated matrices of similarities, but I used the value 0 when the responses of the actors in the dyad were different, and 1 when the values were the same.

\section{(Figure 1)}

\section{NETWORKS}

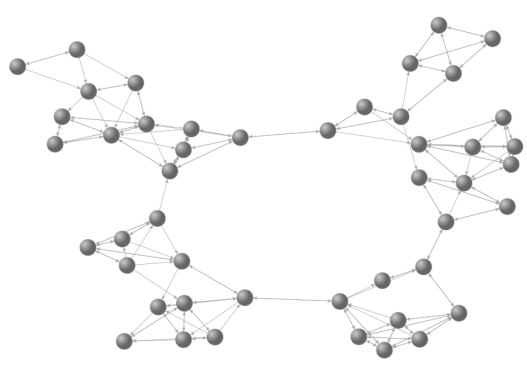

Interaction

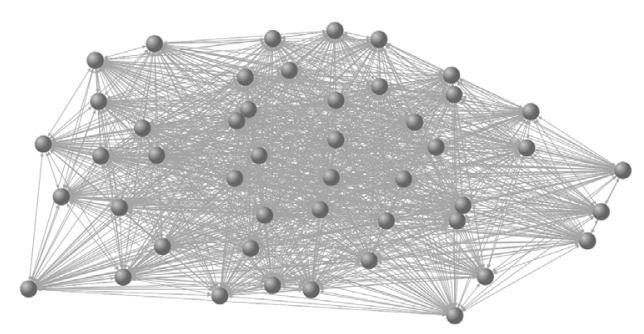

Competence

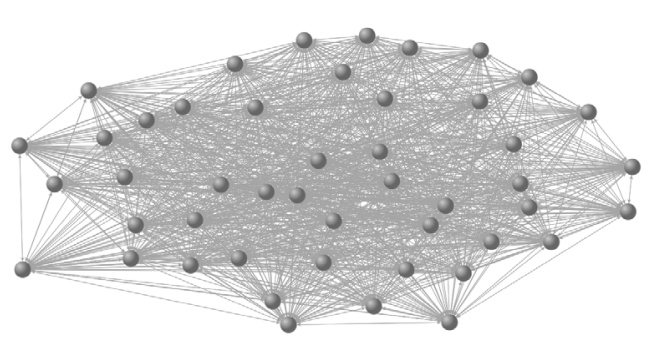

Identification

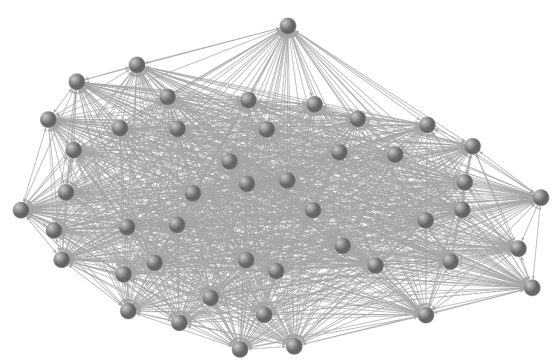

Sociability

Source: Elaborathed by the author in PAJEK (c) 3 software.

\section{DATA ANALYSIS}

The first analysis consisted of a description of the students. Their average age was 21 years, ranging from 20 to 28 . Sixty percent of the students were female, $94 \%$ were single, $70 \%$ did not work, $43 \%$ had advanced English skills, and they had a self-assessed academic performance of 3.12 on a scale 
of 1 to 5 . Forty percent of the students had some institutional ties with some group other than work or the university, and $51 \%$ of their parents had higher education.

My second analysis consisted of testing the hypotheses using the Logistic Regression Quadratic Assignment Procedure (LR-QAP) for dyadic observations, available in UCINET (C) 6.485 software. This logistic regression technique estimates the probability of the occurrence of a response in a binary category and produces more consistent estimates than the MR-QAP technique (Borgatti et al., 2013). The family of QAP techniques consists of regressions of matrices as independent variables and a matrix as a dependent variable. The matrices were generated according to procedures recommended by Borgatti et al. (2013). Therefore, it is necessary that each column of composition data (i.e., non-dyadic) be transformed into a relational data matrix. This is done by composing a square matrix with the names of the actors in the column and vertical, and then the differences for a given variable are calculated between each pair of actors and the diagonal is deducted. For network data already in dyadic relationship matrices, no transformation is required.

The QAP procedure generates a distribution of coefficients by means of permutation of rows and columns of the matrices. This causes the order of the actors to change randomly, even without changing the network structure. The distribution generated from it allows the calculation of the statistical significance of the coefficients (Dekker, Krackhardt, \& Snijders, 2007; Maciel et al., 2014).

The response variable of the first six hypotheses was identification (code 1 for identification and 0 if not). In order to observe the partitioning of the explained variance $\left(\mathrm{R}^{2}\right)$, I tested seven models with the input of the control variables in the first model and the main effect variables in the subsequent models, according to Table 1 . The control variables inserted in the model allowed me to consider the influence of similarity effects on social, demographic, performance, and relational characteristics that theoretically contribute to greater identification, according to Mael and Ashforth (1992) and Dutton et al. (1994). 


\section{(Table 1)}

RESULTS OF LR-QAP MODELS FOR IDENTIFICATION

\begin{tabular}{|c|c|c|c|c|c|c|c|}
\hline & Model 1 & Model 2 & Model 3 & Model 4 & Model 5 & Model 6 & Model 7 \\
\hline Intercept & -1.87 & -1.90 & -1.90 & -1.90 & -1.98 & -4.72 & -6.17 \\
\hline \multicolumn{8}{|l|}{ Control } \\
\hline Academic Performance (S) & 0.31 & 0.31 & 0.31 & 0.31 & $0.34^{*}$ & $0.40^{*}$ & 0.29 \\
\hline School (S) & $0.65^{\star \star \star}$ & $0.67^{\star \star \star}$ & $0.67^{\star \star \star}$ & $0.67^{\star \star \star}$ & $0.39 * *$ & $0.47^{\star \star}$ & 0.18 \\
\hline Civil Status (S) & -0.10 & -0.09 & -0.09 & -0.09 & -0.14 & -0.07 & 0.00 \\
\hline Age (S) & -0.04 & -0.02 & -0.03 & -0.03 & -0.03 & -0.02 & -0.02 \\
\hline English (S) & $0.24^{\star \star}$ & $0.25^{\star *}$ & $0.25^{\star \star}$ & $0.25^{\star *}$ & $0.21^{\star}$ & 0.07 & -0.16 \\
\hline Father's Education (S) & 0.12 & 0.13 & 0.13 & 0.13 & 0.09 & 0.12 & 0.15 \\
\hline Father's Occupation (S) & -0.08 & -0.09 & -0.09 & -0.09 & -0.22 & -0.16 & -0.20 \\
\hline Institutional Ties (S) & 0.01 & 0.01 & 0.01 & 0.01 & -0.12 & -0.01 & -0.08 \\
\hline $\operatorname{Sex}(S)$ & $0.28^{\star \star}$ & $0.28^{\star \star}$ & $0.28^{\star \star}$ & $0.28^{\star *}$ & $0.30^{\star \star}$ & 0.15 & $0.28^{\star}$ \\
\hline Work (S) & 0.12 & 0.11 & 0.11 & 0.11 & 0.09 & 0.07 & 0.12 \\
\hline \multicolumn{8}{|l|}{ Main Effect } \\
\hline Degree Centrality (S) & & $-0.23^{\star \star}$ & $-0.23^{\star \star}$ & $-0.23^{\star \star}$ & $-0.26^{\star \star}$ & -0.01 & -0.13 \\
\hline Local Density (S) & & & 0.06 & 0.05 & 0.06 & 0.07 & 0.03 \\
\hline Structural Holes (S) & & & & -0.01 & -0.01 & -0.10 & -0.12 \\
\hline Structural Equivalence (S) & & & & & $1.58^{\star \star \star}$ & $1.37^{\star \star \star}$ & $0.73^{\star \star \star}$ \\
\hline Competence (S) & & & & & & $0.93^{\star \star \star}$ & $0.62^{\star \star \star}$ \\
\hline Sociability (S) & & & & & & & $1.15^{\text {*** }}$ \\
\hline $\mathrm{LL}$ & 1071.52 & 1053.06 & 1051.89 & 1051.87 & -984.35 & -738.29 & -570.45 \\
\hline$R^{2}$ & $0.03^{*}$ & $0.05^{\star \star}$ & $0.05^{\star *}$ & $0.05^{\star \star}$ & $0.12^{\star \star \star}$ & $0.34^{\star \star \star}$ & $0.54^{\star \star \star}$ \\
\hline Cases & 2162 & 2162 & 2162 & 2162 & 2162 & 2162 & 2162 \\
\hline Permutations & 1000 & 1000 & 1000 & 1000 & 1000 & 1000 & 1000 \\
\hline $\begin{array}{ll}\text { Note: }(S)=\text { Similarity. } \\
\text { * } & p<0.10 \\
\star * & p<0.05 \\
\star * * & p<0.01\end{array}$ & & & & & & & \\
\hline
\end{tabular}

Source: Elaborated by the author. 
I considered Model 7 as a reference for accepting or disregarding the hypotheses. $\mathrm{H}_{1}$ predicted a higher probability of identification according to the similarity of centrality degree, but the result was not statistically significant $(\beta=-0.13, p$-value $>0.10) . \mathrm{H}_{2}$ predicted a higher probability of identification depending on the similarity in local density, but the result also did not confirm the hypothesis $(\beta=0.03, p$-value $>0.10) . \mathrm{H}_{3}$ predicted a greater probability of identification according to the similarity in the proportion of structural holes, but the result was not statistically significant either $(\beta=-0.12, p$-value $>0.10)$. The result of the $\mathrm{H}_{4}$ test confirmed the relationship between the similarity of structural equivalence and dyadic identification $(\beta=0.73$, $p$-value $<0.01) . \mathrm{H}_{5}$, which predicted a relationship between competence deference and dyadic identification, was confirmed with a coefficient of $\beta=0.62$ and $p$-value $<0.01 . \mathrm{H}_{6}$, which predicted a relationship between sociability deference and dyadic identification, was also confirmed $(\beta=1.15$, $p$-value $<0.01)$. The last hypothesis $\left(\mathrm{H}_{7}\right)$, on the influence of mutual identification on group formation, was confirmed ( $\beta=0.48$, $p$-value $<0.01)$ by means of two other regression models, as shown in Table 2.

\section{(Table 2)}

RESULTS OF LR-QAP MODELS FOR WORKING GROUPS

\begin{tabular}{|c|c|c|}
\hline & Model 1 & Model 2 \\
\hline Intercept & -6.70 & -6.60 \\
\hline \multicolumn{3}{|l|}{ Control } \\
\hline Academic Performance (S) & 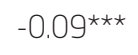 & $-0.09 * \star \star *$ \\
\hline School (S) & -0.31 & -0.32 \\
\hline Civil Status (S) & 0.16 & 0.15 \\
\hline Age (S) & $-0.02^{\star \star \star}$ & $-0.02^{\star \star \star}$ \\
\hline English (S) & -0.04 & -0.01 \\
\hline Father's Education (S) & -0.10 & -0.11 \\
\hline Father's Occupation (S) & -0.15 & -0.15 \\
\hline Institutional Ties (S) & 0.06 & 0.06 \\
\hline $\operatorname{Sex}(S)$ & $0.79 \star \star$ & $0.78^{\star \star}$ \\
\hline Work (S) & 0.04 & 0.04 \\
\hline
\end{tabular}




\begin{tabular}{|c|c|c|}
\hline \multicolumn{3}{|c|}{ RESULTS OF LR-QAP MODELS FOR WORKING GROUPS } \\
\hline & Model 1 & Model 2 \\
\hline Degree Centrality (S) & $0.05^{\star \star \star}$ & -0.02 \\
\hline Local Density (S) & $-0.03^{\star \star \star}$ & $-0.03^{\star \star \star}$ \\
\hline Structural Holes (S) & $-0.05^{\star \star \star}$ & $0.08^{\star \star \star}$ \\
\hline Structural Equivalence (S) & $2.45^{\star \star \star}$ & $2.40^{\star \star \star}$ \\
\hline Competence (S) & $0.07^{\star \star}$ & $0.06^{\star}$ \\
\hline Sociability (S) & $0.98^{\star \star \star}$ & $0.89^{\star \star \star}$ \\
\hline \multicolumn{3}{|l|}{ Main Effect } \\
\hline Mutual Identification & & $0.48^{\star \star \star}$ \\
\hline LL & -298.86 & -299.58 \\
\hline $\mathrm{R}^{2}$ & 0.42 & 0.43 \\
\hline$\Delta R^{2}$ & 0.00 & 0.01 \\
\hline Cases & 2162 & 2162 \\
\hline Permutations & 1000 & 1000 \\
\hline $\begin{array}{ll}\text { Note: }(S)=\text { Similarity. } \\
\text { * } & p<0.10 \\
* \star & p<0.05 \\
* \star \star & p<0.01\end{array}$ & & \\
\hline
\end{tabular}

\section{DISCUSSION OF RESULTS}

In the first stage of data analysis (see Table 1), I estimated the influence of two types of similarity: structural (ties pattern level) and deferential (ties level) similarity of identification in the classroom. The results highlighted that, unlike the findings that supported my hypotheses, the similarity in the measures of prominence, cohesion, and intermediation (Nooy et al., 2005) did not increase the probability of identification among the students. Positional similarity (structural equivalence), in turn, presented a $\beta=0.73$ and $p$-value $<0.01$ (Model 7), allowing the acceptance of only $\mathrm{H}_{4}$ among the first four hypotheses that dealt with the effects of structural similarity. Such results provide at least two possible explanations. 
The first and most obvious is that the degree of centrality, the degree of local density, and the proportion of structural holes have a not significant effect on identification, because they are not parameters that are seen as important for students to delineate categories or structural self-categorization profiles (Hornsey, 2008; Turner et al., 1987). The results confirm that only structural equivalence can fulfill this role, because when actor $i$, for example, shares the same ties as actor $j, i$ and $j$ are under the same behavioral expectations and, therefore, would act in a similar way. The behavior similarity, caused by the same pattern of ties between $i$ and $j$ (Mizruchi, 1993), would then be a significant basis for assessing the homogeneity of conduct and the greater harmony between them, thus constituting the dyadic identification in the classroom.

The second explanation alternative is that even if such characteristics are seen as important for self-categorization and identification, it is possible that social actors do not have an accurate perception of their measures and of those of their peers in terms of prominence, cohesion, and intermediation (Neal et al., 2016). This argument weakens the position of Nooy et al. (2005), who affirm that there is a significant correlation between such measures and the actor's perception toward them. Perhaps the most accurate perception of a sociometric measure occurs more easily only in the case of structural equivalence, due to a greater probability of interaction existing between two actors that have the same contacts in their interactions (Mizruchi, 1993). Regardless, in comparison with other measures of the interaction network, the proof of the effects of structural equivalence on identification deserves attention.

In this first stage of analysis, I estimated the influence of deference networks (Lomi \& Torló, 2014) on identification. It is worth noting in Table 1 that control variables (Model 1) in the first regression analysis aided to explain about $3 \%$ of the probability of identification occurrence. The insertion of 4 measures of the interaction networks (Model 5) explained why the variance changed to $12 \%$, but when the first measure of deference similarity (competence) was inserted in Model 6, the explained variance value jumped to $34 \%$, and then to $54 \%$ with the insertion of the sociability similarity variable. A substantial increase in $\mathrm{R}^{2}$ values with measures of deference is also worth noting, as they evidence the weight of social judgment in dyadic identification (Kervyn et al., 2010; Fiske et al., 2012). As observed, similar students in structural equivalence are more likely to identify with one another. However, the chances of identification increase further when the similarity resides in deferential characteristics of competence and 
sociability. Two students of equal competence or ability to have fun are more likely to identify with each other. However, when looking at the coefficients of the two measures (Model 7 in Table 1), they appear to be quite different. The competence has a $\beta=0.62$ coefficient and $p$-value $<0.01$, while sociability has a $\beta=1.15$ coefficient and $p$-value $<0.01$. This suggests that fun is the main element of comparison in the identification process of one student with another in the classroom.

In the second stage of data analysis (see Table 2), I aimed at evaluating if dyadic identification in the classroom would be important in relational terms. Thus, I assessed the effects of identification on the composition of final course assignment groups in the Business Administration course. All control variables used in the models of Table 1 for testing the first six hypotheses were maintained, and the similarity variables of the interaction and deference networks were added as new control variables. This allowed me to observe whether, even in the presence of all other variables of similarity of network measures and composition (Wasserman \& Faust, 2009), the identification would still be statistically significant in the formation of the final course assignment groups. Model 1 of Table 2 shows that control variables have a substantial power of explanation $\left(R^{2}=0.42\right)$ of the probability of two similar actors in a network and composition variables being in the same working group. Model 2 of Table 2, in which I inserted identification as the main effect variable, has a $R^{2}=0.43$. Although there was no significant increase in the explanatory power of working group formation, the dyadic identification variable is statistically significant ( $\beta=$ 0.48 , $p$-value $<0.01$ ). This result reinforces the idea that group formation is oriented not only by sociometric and deferential characteristics but also directly by a particular kind of subjectivity, which is the dyadic identification (Leung \& Wang, 2015; Hu \& Liden, 2015; Crawford \& Lepine, 2013). More specifically, this corroborates this study's initial argument that the feeling of belonging to certain social categories of referent does not only occur in relation to large collectivities, as stated by the Theory of Social Identity (Tajfel, 1978; Tajfel \& Turner, 1979), but also through the dyads of the actors in the networks.

Moreover, since most of the explanatory power of working group formation lies in the set of control variables, it is important to highlight that among them sociability has a substantial effect regarding the statistical coefficient and significance in Model $2(\beta=0.89, p$-value $<0.01)$. Competence, in turn, has a much lower coefficient $(\beta=0.06)$ and is statistically significant only when I consider a $p$-value $<0.10$. However, the variable explaining the 
formation of the working groups with the greatest coefficient in Model 2 of Table 2 is the structural equivalence $(\beta=2.40, p$-value $<0.01)$. It is a noteworthy finding that students defined the composition of their final course assignment groups as being guided primarily (even considering the comparison between the sizes of coefficients rather than the sizes of effects) by the following: similarity in the ties pattern of the interaction network (i.e., structural equivalence), similarity in sociability deference (i.e., fun), sex similarity, and mutual identification, leaving very little to be explained by the similarity of competences deference $(\beta=0.06, p$-value $<0.10)$.

In general, the results highlight that a substantial part of the dynamics of student relationships within the classroom space (Boocock, 1978) is exemplified by identification between social actors at a dyadic level, and can be understood from the Social Networks Analysis Perspective. As shown herein, this perspective allows for the analytic separation of the effects of interaction and deference networks (Lomi \& Torló, 2014). This separation was important regarding analysis because the results show that only one of the sociometric indicators of focal actors was able to explain identification. However, a logic of social judgment based on deferences of competence and sociability might substantially increase the explanatory power of dyadic identification (Kervyn et al., 2010; Fiske et al., 2012). Moreover, it was found that identification in the classroom has an important relational consequence: the composition of final course assignment groups.

\section{CONCLUSIONS}

Before remembering the objective of this study and presenting the conclusions, it is necessary to consider some limitations that marked the development of the study. The first limitation is that the formation of final course assignment groups was probably influenced by previous episodes, such as the formation of groups to develop assignments in various disciplines during the course. It is difficult to imagine that the assignment groups in the disciplines would not influence the patterns of interaction, which in turn influenced the formation of the final course assignment group. As the study does not have this history in different disciplines, it is necessary to consider this limitation when reading the results. The research universe can also be considered a limitation, since the research was restricted to only one class. However, these limitations point to the possibility of future studies with more than two moments of data collection, perhaps even during 
the entire course, so that the formation of working groups in different disciplines and their effects in the final course assignment group can be mapped.

My objective in performing this study was to rescue the idea of nonanthropomorphized social identification, that is, between human social actors, and to evaluate if interaction and deference networks (symbolic peer assessments) could explain this phenomenon among students in a given educational space. Moreover, I tried to verify if dyadic identification could be something important-that is, if it had some consequence, mainly of a relational nature.

The results showed that, among the different groups of sociometric measures, only the structural equivalence, coming from interaction networks, contributed to explain the greater probability of dyadic identification in the classroom. However, I also found that symbolic assessments of peer competence and sociability further explained the probability of identifying one student with another. In the test of one relational consequence of dyadic identification in the classroom, the results allowed me to prove the statistically significant influence of such phenomena in the composition of the final course assignment groups.

I concluded from the results of this study that, together, the structural equivalence, the deferences of competence, and sociability constitute a structural-deferential basis of a social judgment that enables the construction of social profiles and categories, which, in turn, allows for comparison between the pairs and the subsequent potential identification. This conclusion contributes to the literature on identification at a dyadic level (Rink, \& Ellemers, 2007, 2008; Burgoon et al., 1995) by presenting the different roles of elements at the relational level of ties, as well as at the pattern or structural level of ties. Although measures taken from ties patterns have presented a reasonable explanatory power, the content measures, therefore, at ties level (i.e., sociability and competence), have substantially increased the explanatory power of the dyadic identification prediction model. In this sense, this work also contributes to the field of Social Networks Analysis by exploring the different effects of the content and structure of relationships in an attitudinal variable.

Moreover, I have found that the formation of working groups should be seen as a result of the strength of identification at the dyadic level, the typical level of the Social Networks Analysis Perspective, and not only as a result of the identification at the collective level, as previously stated by the Theory of Social Identity. The main theoretical contribution of this study is to consider identification as a non-anthropomorphic and dyadic phenomenon, studied from interactions and deference networks in the classroom. 
As recommendation for further studies, it is possible to highlight the need for longer temporal amplitude with more waves of data collection in Business Administration classes, coupled with a comparison of the results with results from other courses. Another research opportunity is the investigation of these surveys in intra-organizational networks. Such studies will allow for the exploration of the structural and deferential aspects of social judgment and, therefore, point out, for example, informal leadership from measures of higher status in competence and sociability deference.

\section{REFERENCES}

Boocock, S. S. (1978). The social organization of the classroom. Annual Review of Sociology, 4(1), 1-28. doi 10.1146/annurev.so.04.080178.000245 Borgatti, S. P., \& Halgin, D. S. (2011). On network theory. Organization Science, 22(5), 1168-1181. doi 10.1287/orsc.1100.0641

Borgatti, S. P., Brass, D. J., \& Halgin, D. S. (2014). Social network research: confusions, criticisms, and controversies. In D. J. Brass, G. Labianca, A. Mehra, D. S. Mehra, \& S. P. Borgatti (Eds.). Contemporary perspectives on organizational social networks (vol. 40, pp.1-32). Bingley: Emerald Publishing.

Borgatti, S. P., Everett, M. G., \& Johnson, J. C. (2013). Analyzing social networks. Thousand Oaks: Sage Publications.

Burgoon, J. K., Le Poire, B. A., \& Rosenthal, R. (1995). Effects of preinteraction expectancies and target communication on perceiver reciprocity and compensation in dyadic interaction. Journal of Experimental Social Psychology, 31 (4), 287-321. doi 10.1006/jesp.1995.1014

Burt, R. S. (1992). Structural holes: The social structure of competition. Cambridge: Harvard University Press.

Conti, N., \& Doreian, P. (2010). Social network engineering and race in a police academy: A longitudinal analysis. Social Networks, 32 (1), 30-43. doi 10.1016/j.socnet.2009.08.001

Crawford, E. R., \& Lepine, J. A. (2013). A configural theory of team processes: Accounting for the structure of taskwork and teamwork. Academy of Management Journal, 38(1), 32-48. doi 10.5465/amr.2011.0206

Dahlander, L., \& McFarland, D. A. (2013). Ties that last: Tie formation and persistence in research collaborations over time. Administrative Science Quarterly, 58(1), 69-110. doi 10.1177/0001839212474272 
Dawson, S. (2008). A study of the relationship between student social networks and sense of community. Educational Technology \& Society, 11(3), 224-238.

Dekker, D., Krackhardt, D., \& Snijders, T. A. B. (2007). Sensitivity of MRQAP tests to collinearity and autocorrelation conditions. Psychometrika, 72(4), 563-581. doi 10.1007/s11336-007-9016-1

Dutton, J. E., Dukerich, J. M., \& Harquail, C. V. (1994). Organizational images and member identification. Administrative Science Quarterly, 39(2), 239-263. doi 10.2307/2393235

Emirbayer, M. (1997). Manifest for a relational sociology. American Journal of Sociology, 103(2), 281-317. doi 10.1086/231209

Emirbayer, M., \& Goodwin, J. (1994). Network analysis, culture, and the problem of agency. American Journal of Sociology, 99(6), 1411-1454. doi 10.1086/ 230450

Fiske, S. T., Cuddy, A. J. C., \& Glick, P. (2007). Universal dimensions of social cognition: warmth and competence. Trends in Cognitive Sciences, 11 (2), 77-83. doi 10.1016/j.tics.2006.11.005

Fombelle, P. W., Jarvis, C. B., Ward, J., \& Ostrom, L. (2012). Leveraging customers' multiple identities: Identity synergy as a driver of organizational identification. Journal of the Academy Marketing Science, 40(4), 587-604. doi 10.1007/s11747-011-0254-5

Granovetter, M. (1973). The strength of weak ties. American Journal of Sociology, 78(6), 1360-1380. doi 10.1086/225469

Granovetter, M. (1990). The myth of social network analysis as a special method in the social sciences. Connections, 13(1), 13-16.

Hornsey, M. J. (2008). Social identity theory and self-categorization theory. Social and personality Psychology Compass, 2(1), 204-222. doi 10.1111/j. 1751-9004.2007.00066.x

Hu, J., \& Liden, R. C. (2015). Making a difference in the teamwork: Linking team prosocial motivation to team processes and effectiveness. Academy of Management Journal, 58(4), 1102-1127. doi 10.5465/amj.2012.1142

Huitsing, G., Veenstra, R., Sainio, M., \& Salmivalli, C. (2012). "It must be me" or "It could be them?": The impact of the social network position of bullies and victims or victims adjustment. Social Networks, 34(4), 379-386. doi 10.1016/j.socnet.2010.07.002

Johnson, S. A., Ashforth, B. E. (2008). Externalization of employment in a service environment: The role of organizational and customer identification. Journal of Organizational Behavior, 29(3), 287-309. doi 10.1002/job.477 
Jones, C., \& Volpe, E. H. (2011). Organizational identification: extending our understandings of social identities through social networks. Journal of Organizational Behavior, 32 (3), 413-434. doi 10.1002/job.694

Kadushin, C. (2012). Understanding social networks: theories, concepts, and findings. New York: Oxford University Press.

Kervyn, N., Yzerbyt, V., \& Judd, C. M. (2010). Compensation between warmth and competence: Antecedents and consequences of a negative relation between the two fundamental dimensions of social perception. European Review of Social Psychology, 21 (1), 155-187. doi 10.1080/13546805. 2010.517997

Kilduff, M., \& Tsai, W. (2012). Social networks and organizations. Thousand Oaks: Sage.

Kilduff, M., Tsai, W., \& Hanke, R. (2006). A paradigm too far? A dynamic stability reconsideration of the social network research program. Academy of Management Review, 31 (4), 1031-1048. doi 10.5465/AMR.2006.22528168

Knippenberg, D., \& Schie, E. C. M. (2000). Foci and correlates of organizational identification. Journal of Occupational and Organizational Psychology, 73(1), 137-147. doi 10.1348/096317900166949

Lee, C. C., \& Chang, J. W. (2013). Does trust promote more teamwork? Modeling online game player's teamwork using team experience as a moderator. Cyberpsychology, Behavior, and Social Networking, 16(11), 813-819. doi 10.1089/cyber.2012.0461

Lee, C., Farh, J. L., \& Chen, Z. J. (2011). Promoting group potency in project teams: the importance of group identification. Journal of Organizational Behavior, 32 (8), 1147-1162. doi 10.1002/job.741

Leszczensky, L., \& Pink, S. (2015). Ethnic segregation of friendship networks in school: Testing a rational-choice argument of differences in ethnic homophily between classroom and grade-level networks. Social Networks, 42(1), 18-26. doi 10.1016/j.socnet.2015.02.002

Leung, K., \& Wang, J. (2015). Social processes and team creativity in multicultural teams: A socio-technical framework. Journal of Organizational Behavior, 36(7), 1008-1025. doi 10.1002/job.2021

Lomi, A., \& Torló, V. J. (2014). The network dynamics of social status: problems and possibilities. In D. J. Brass, G. Labianca, A. Mehra, D. S. Halgin, \& S. P. Borgatti (Eds.). Contemporary perspectives on organizational social networks (Vol. 40, pp. 403-420). Bingley: Emerald Publishing. 
Maciel, C. O., \& Camargo, C. (2015). Conexão social intraorganizacional, suporte no trabalho e identificação organizacional. Revista de Administração Contemporânea, 19(3), 348-366. doi 10.1590/1982-7849rac20152017

Maciel, C. O., Taffarel, M., \& Camargo, C. (2014). Embeddedness estrutural e espacial em redes estratégicas: efeitos atitudinais no nível das díades. Revista de Administração Mackenzie, 15(3), 166-190. doi 10.1590/167869712014/administracao.v15n3p166-190

Mael, F., \& Ashforth, B. E. (1992). Alumni and their alma mater: a partial test of the reformulated model of organizational identification. Journal of Organizational Behavior, 13(2), 103-123. doi 10.1002/job.4030130202

Marra, A. V., Fonseca, J. A., \& Marques, A. L. (2014). O processo de identificação organizacional frente à Reforma Administrativa: um estudo exploratório. Revista de Administração Mackenzie, 15(1), 49-72. doi 10.1590/ S1678-69712014000100003

Marsden, P. V. (2011). Survey methods for network data. In J. Scott, \& J. P. Carrington (Eds.). The Sage handbook of social network analysis (pp. 370-388). Thousand Oaks: Sage.

Millward, L. J., \& Postmes, T. (2010). Who we are affects how we do: the financial benefits of organizational identification. British Journal of Management, 21 (2), 327-339. doi 10.1111/j.1467-8551.2009.00667.x

Mishra, S. K., \& Bhatnagar, D. (2010). Linking emotional dissonance and organizational identification to turnover intention and emotional wellbeing: a study of medical representatives in India. Human Resource Management, 49(3), 401-419. doi 10.1002/hrm.20362

Mizruchi, S. M. (1993). Cohesion, equivalence, and similarity of behavior: a theoretical and empirical assessment. Social Networks, 15(2), 275-307. doi 10.1016/0378-8733(93)90009-A

Neal, J. W., Neal, Z. P., \& Cappella, E. (2016). Seeing and being seen: predictors of accurate perceptions about classmates' relationships. Social Networks, 44(1), 1-8. doi 10.1016/j.socnet.2015.07.002

Nooy, W., Mrvar, A., \& Batagelj, V. (2005). Exploratory social network analysis with Pajek. Cambridge: Cambridge University Press.

Obst, P. L., White, K. M., Mavor, K. I., \& Baker, R. M. (2011). Social identification dimensions as mediators of the effect of prototypicality on intergroup behaviours. Psychology, 2(5), 426-432. doi 10.4236/psych. 2011.35066 
Ortiz, M. G. R., Hoyos, J. R. C., \& López, M. G. R. (2004). The social networks of academic performance in a student context of poverty in Mexico. Social Networks, 26(2), 175-188. doi 10.1016/j.socnet.2004.01.010

Rink, F., \& Ellemers, N. (2007). Defining the common feature: task-related differences as the basis for dyadic identity. British Journal of Social Psychology, 46(3), 499-515. doi 10.1348/014466606X154872

Rink, F., \& Ellemers, N. (2008). Diversity, newcomers, and team innovation: The importance of a common identity. In E. Mannix, M. A. Neale, \& K. W. Phillips (Eds.). Diversity and groups: Research on managing groups and teams (pp. 221-243). Bingley: Emerald Publishing Limited.

Schmid, K., \& Muldoon, O. T. (2015). Perceived threat, social identification, and psychological well-being: The effects of political conflict exposure. Political Psychology, 36(1), 75-92. doi 10.1111/pops.12073

Sluss, D. M., \& Ashforth, B. E. (2007). Relational identity and identification: defining ourselves through work relationships. Academy of Management Review, 32(1), 9-32. doi 10.5465/AMR.2007.23463672

Sluss, D. M., \& Ashforth, B. E. (2008). How relational and organizational identification converge: Processes and conditions. Organization Science, 19(6), 807-823. doi 10.1287/orsc. 1070.0349

Steglich, C., Sinclair, P., Holliday, J., \& Moore, L. (2012). Actor-based analysis of peer influence in A Stop Smoking in Schools Trials (ASSIST). Social Networks, 34(3), 359-369. doi 10.1016/j.socnet.2010.07.001

Stovel, K., \& Shaw, L. (2012). Brokerage. Annual Review of Sociology, 38(1), 139-158. doi 10.1146/annurev-soc-081309-150054

Tajfel, H. (1978). Differentiation between social groups: studies in the social psychology of intergroup relations. London: Academic Press.

Tajfel, H., \& Turner, J. (1979). An integrative theory of intergroup conflict. In W. Austin \& S. Worchel (Eds.). The social psychology of intergroup relations (pp. 33-47). Monterey, CA: Brooks/Cole.

Torló, V. J., \& Lomi, A. (2017). The networks dynamics of status: assimilation and selection. Social Forces, 96(1), 389-422. doi 10.1093/sf/sox040

Turner, J. C., Hogg, M. A., Oakes, P. J., Reicher, S. D., \& Wetherell, M. S. (1987). Rediscovering the social group: A self-categorization theory. Oxford: Basil Blackwell.

Wasserman, S., \& Faust, K. (2009). Social network analysis. Cambridge: Cambridge University Press. 
Wieseke, J., Kraus, F., Ahearne, M., \& Mikolon, S. (2012). Multiple identification foci and their countervailing effects on salespeople's negative headquarters stereotypes. Journal of Marketing, 76(1), 1-20. doi 10.1509/ jm.10.0444

\section{ABOUT THE AUTHOR}

\section{CRISTIANO DE OLIVEIRA MACIEL}

$\mathrm{PhD}$ in Management from the Department of Management,

Pontifical University Catholic of Parana.

Full Professor from the Department of Management,

Pontifical University Catholic of Parana.

R. Imaculada Conceição, 1155, Prado Velho - Curitiba - PR - Brazil - CEP 80215-901

E-mail: cristiano.maciel@pucpr.br

ORCID: 0000-0002-4103-0770

EDITORIAL BOARD

Editor-in-chief

Silvio Popadiuk

Associated Editor

Dimária Silva e Meirelles

Technical Support

Patricia Betencourt

Vitória Batista Santos Silva

\section{EDITORIAL PRODUCTION}

Publishing Coordination

Irina Migliari

Language Editor

Caio Rubens Salles

Editorial Trainee

Maria Luiza Vanz

Layout Designer

Emap

Copyeditor

Irina Migliari

Graphic Designer

Libro 